\title{
Periprosthetic fractures of the femur after total knee arthroplasty
}

\author{
Phil McGraw • Arun Kumar
}

Received: 27 October 2009/Accepted: 29 June 2010/Published online: 27 July 2010

(C) The Author(s) 2010. This article is published with open access at Springerlink.com

\begin{abstract}
Periprosthetic fracture following total knee arthroplasty is a potentially serious complication. This injury can involve the distal femur, proximal tibia or the patella. This review article analyzes the prevalence, risk factors, classification and treatment options for periprosthetic fractures of the femur.
\end{abstract}

Keywords Periprosthetic fracture $\cdot$ Femur $\cdot$ Knee arthroplasty

\section{Introduction}

Incidence of periprosthetic fracture following total knee arthroplasty is gradually increasing, and management of these fracture can be challenging for orthopaedic surgeons. In a systematic review of 415 cases, Herrera et al. reported a nonunion rate of $9 \%$, fixation failure in $4 \%$, an infection rate of $3 \%$ and revision surgery rate of $13 \%$ [1]. This review article analyzes the various risk factors, proposed classification systems and treatment options for periprosthetic fractures of the femur after total knee arthroplasty.

\section{Epidemiology and pathogenesis}

Incidence of distal femoral metaphyseal periprosthetic fractures associated with total knee replacement has been

P. McGraw · A. Kumar

Department of Orthopaedics, University Hospital

of South Manchester, Manchester M23 9LT, UK

A. Kumar $(\bowtie)$

170, Woodhouse Lane, Sale, Cheshire M33 4LN, UK

e-mail: arun_orth@yahoo.co.uk reported to range between $0.3 \%$ and $2.5 \%$ [2-5]. Majority of these fractures occur following minor trauma after a simple fall. Other causes include road-traffic accidents, seizures and forced manipulation of a stiff knee. There are many risk factors which can predispose to these fractures. These include osteoporosis [6-8], anterior femoral notching [6-9], rheumatoid arthritis [6, 10-12], steroid therapy [1, 10-12], neurological diseases [3], previous revision arthroplasty [6, 7] and local osteolysis and infection $[5,13]$. A biomechanical study has shown that notching of the anterior cortex significantly lessens the load to failure by decreasing the bending strength by $18 \%$ and torsional strength by about $40 \%$ [9]. Ritter et al., however, in a clinical study, did not find any relation between anterior notching of the distal femur and occurrence of periprosthetic fractures. They reviewed 1,089 cases at an average follow-up of 5 years and noted anterior notching in $29.8 \%$ of cases. During this period there were only two cases of periprosthetic fractures in this group, and both were in femora treated without notching [14]. Unlike periprosthetic fractures of the tibia, malalignment has not been shown to be a causative factor for periprosthetic fracture of the femur [6].

\section{Classification}

Numerous classifications of supracondylar femoral fractures after total knee arthroplasty have been described [15-17]. The most commonly used classification was developed by Rorabeck and Taylor [16]. This classification takes into account fracture displacement and prosthesis condition (well fixed or loose).

Type I: undisplaced fracture and prosthesis is well fixed Type II: displaced fracture and prosthesis is well fixed 
Type III: prosthesis is loose, fracture may be displaced or undisplaced

\section{Management}

The aim of treatment in fractures of the distal femur proximal to total knee arthroplasty is to achieve a painless and stable knee without significant residual malalignment. Choice of treatment depends on condition of the knee prosthesis (loose or well fixed), the fracture pattern, quality of bone stock, presence of any other implant in the proximal femur and general physical condition of the patient.

\section{Nonoperative treatment}

Nonoperative treatment involves application of a cast brace with or without a period in skeletal traction. Some studies have reported good results after nonoperative treatment $[2,7,10,18]$. Sisto et al. recommended closed reduction and skeletal traction as primary treatment of these fracture and to consider surgical option only if satisfactory alignment could not be maintained. However, this may be associated with difficulty in maintaining reduction, prolonged period of immobilisation, reduced knee functions, malunion and nonunion. Culp et al. discouraged use of closed methods, as conservative treatment was followed by nonunion in $20 \%$ and malunion in $23 \%$ patients in their study [3]. Merkell and Johnson recommended conservative treatment in their study, although 9 out of 26 patients (35\%) required revision arthroplasty because of nonunion, malunion, loosening of components and extensor lag [6]. Moran et al. reported satisfactory results in five undisplaced fractures managed with closed treatment, but none of the nine patients with displaced fracture achieved satisfactory results after nonoperative treatment [19].

In summary, conservative management using a hinged cast brace and restricted weightbearing may be advocated if the fracture is found to be undisplaced and the component is thought to be stable based on radiographic evidence (type I fractures). Patients should be closely followed with routine radiograph to ensure that satisfactory alignment is maintained throughout the treatment period. In an event of loss of alignment and reduction, surgical intervention is required. Displaced fractures should be treated by surgery to avoid complications of nonoperative treatment.

\section{Operative treatment}

There are several surgical options to treat periprosthetic fractures of the distal femur. If the implant is stable, then osteosynthesis by any appropriate means with or without bone graft would be recommended. However, if the prosthesis is loose, then a major reconstruction with revision to a stemmed component is required.

Open reduction and internal fixation using conventional plates

Open reduction and internal fixation allows anatomical reconstruction and early rehabilitation of the patient. Several authors have reported good results after open reduction and internal fixation of these fractures [20-22]. Healy et al. treated 20 fractures with open reduction and internal fixation using a variety of different implants including blade plate, condylar screw and condylar buttress plates. They performed bone grafting in 15 patients and achieved union in 18 patients. Two patients, who did not have bone graft at the time of index surgery, needed reoperation with bone grafting to achieve union. Authors recommended primary bone grafting with internal fixation to increase the chances for union of these difficult fractures, to which blood supply has been compromised by previous total knee arthroplasty, the fracture itself and the operative fixation of the fracture [21]. However, achieving rigid internal fixation could be technically demanding in osteopenic and comminuted bones. Figgie et al. reported union in only five out of ten cases after open reduction and internal fixation. The remaining five patients needed further surgical procedures. They also noted that eight out of ten cases developed varus alignment despite satisfactory intraoperative alignment due to metaphyseal comminution, and this was associated with development of progressive radiolucent lines around the prostheses [4]. Moran et al. treated 15 patients with condylar screw and plates, blade plates and buttress plates. Of these 15 patients, 2 developed malunion and 3 nonunion at the fracture site requiring further surgery [19]. Cordeiro et al. reported varus angulation in all three patients in their series who were managed with plate and screws [22].

Various different methods have been used to enhance the fixation using internal fixation. Zehntner and Ganz used polymethylmethacrylate to enhance the fixation in oeteopenic bone, achieving union in all six patients in their series [23]. Tani et al. reported a case in which they used intramedullary fibular autograft to help restore bone stock and achieve quadri-cortical fixation for screws [24]. However this technique has not been widely used because of graft donor-site morbidity, particularly in elderly patients. Wang and Wang reported satisfactory results using combination of medial allograft struts and a compression plate for fractures above a total knee replacement with severe osteopenia or loss of bone stock and failure of initial open reduction and internal fixation [25]. Kumar et al. reported using intramedullary fibular strut allograft in three patients who had very low and comminuted 
Fig. 1 Radiographs of the knee joint, showing a very low periprosthetic fracture of the distal femur
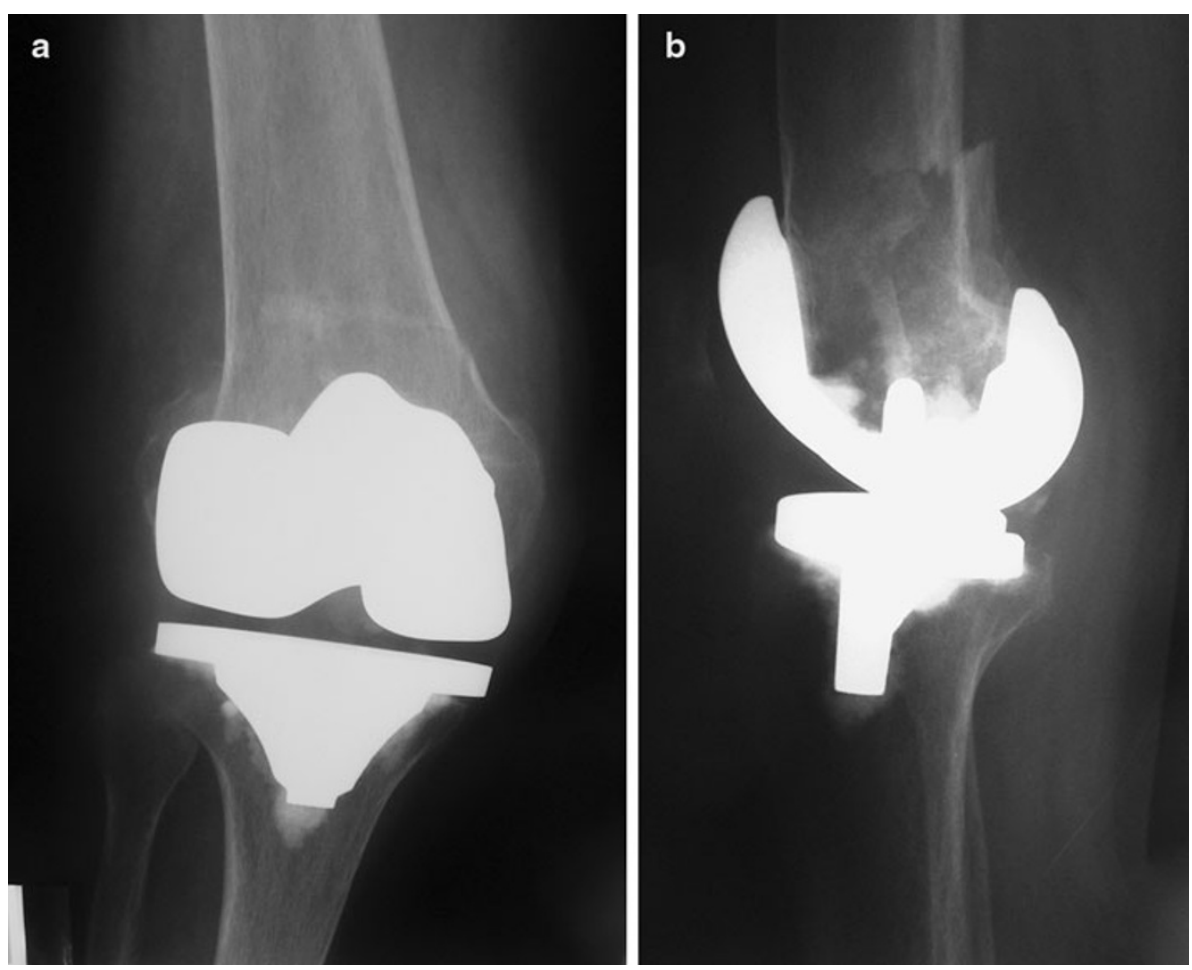

periprosthetic fractures of the distal femur, with good results (Figs. 1, 2). They believe that intramedullary allograft offers both mechanical and biological advantage and enhances implant fixation [26].

\section{Locking plates}

New locking plates offer advantages over conventional plates for the treatment of periprosthetic fracture associated with total knee arthroplasty. These devices provide stable fixation in osteopenic bone, are adaptable to different types of fracture and prosthesis and can be inserted using a minimally invasive approach. These plates are particularly useful in presence of an implant in proximal femur as it allows unicortical screw fixation overlapping the distal part of the proximal implant, thus avoiding a stress riser between the two implants. Biomechanical studies using paired cadaver femurs have demonstrated that fixation with locked plates is superior to that with plates with non-locked screws including blade plate and dynamic condylar screw [27, 28]. Clinical studies have also reported good results using locking plates for the treatment of periprosthetic supracondylar femur fractures [29-32]. Kregor et al. reported $100 \%$ union rate in 13 periprosthetic fractures using locking plate; only one patient needed bone grafting [29]. Althausen et al. reported better results using less invasive stabilization system (LISS) plate in terms of maintenance of alignment and early return to preoperative functional status as compared with three other devices [30].
Raab and Davis reported their results of using locking plate in 11 fractures, which included 2 nonunions. Eight fractures were supplemented with non-structural allograft. All patients were advised limited weightbearing, and seven patients needed a brace postoperatively. They achieved union in all nine acute fractures and in one case of nonunion with satisfactory alignment [31]. Ricci et al. reported their results of treating 22 periprosthetic fractures by indirect reduction methods without bone graft using a locking plate. Nineteen of 22 fractures $(86 \%)$ healed after the index procedure. All three patients who failed to heal were insulin-dependent diabetes mellitus patients. Two of these patients developed infected nonunion. Authors concluded that fixation of periprosthetic supracondylar femur fractures with a locking plate provided satisfactory results in nondiabetic patients [32].

\section{Intramedullary fixation}

Flexible intramedullary rods have been used to treat periprosthetic fractures around the knee. Ritter et al. reported their results in 22 patients, achieving union in all cases without any major complications. The average postoperative alignment was $10^{\circ}$, with two fractures healing in $15^{\circ}$ of valgus malalignment [33]. These flexible rods provide very little rotational and axial stability, and with the advent of rigid retrograde nails these rods are rarely used. The available literature suggests that supracondylar nailing is a simple, safe and minimally invasive procedure. Many 
Fig. 2 Radiographs of the knee joint 6 months after internal fixation using an intramedullary fibular allograft and a plate showing fracture union and restoration of bone stock
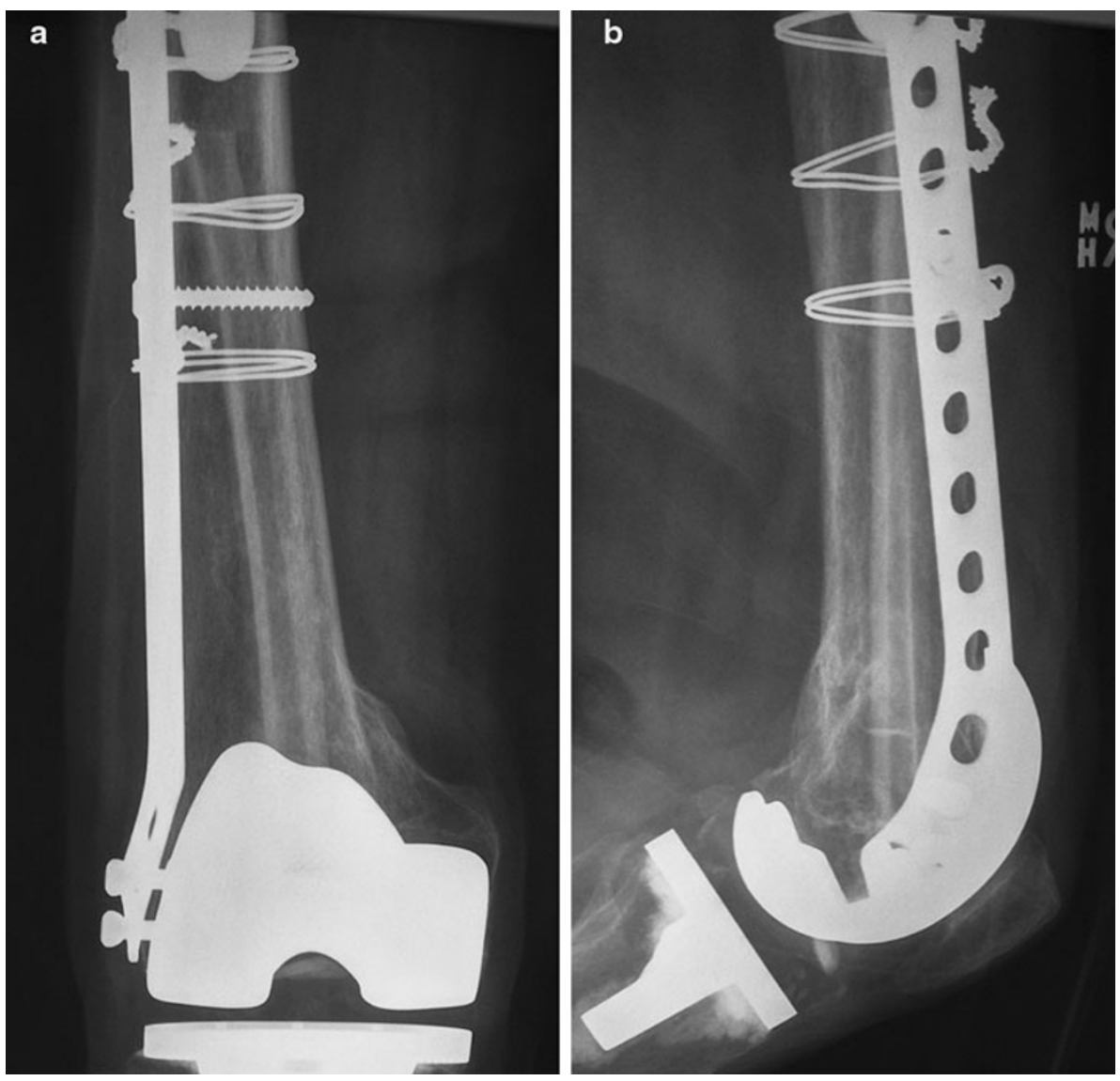

studies have now shown high success rate with the use of supracondylar nail in the management of periprosthetic fractures of the distal femur [11, 34-40]. A cadaveric study has reported greater fracture stability with the use of a retrograde nail as compared with less invasive stabilization system in simulated periprosthetic fractures [41]. This technique uses the previous incision, and no soft tissue dissection is required at the fracture site. It allows early mobilisation and range-of-motion exercises of the knee joint and maintains the overall alignment at the fracture site. A recent systematic review of 415 cases of periprosthetic fracture above knee arthroplasty reported that retrograde nailing is associated with relative risk reduction of $87 \%$ for developing a nonunion and $70 \%$ for requiring revision surgery compared with traditional (non-locking) plating methods [1]. However, this technique also has some limitations. It is not possible to use a supracondylar nail in a very distal fracture, as it may not provide any fixation to the distal screws. A supracondylar nail should not be used in presence of a pre-existing total hip replacement, as it can create a stress riser below the femoral stem leading to a fracture between the two implants. Although most of the modern knee prostheses would allow insertion of a supracondylar nail, it is important to determine the type of the knee implant before surgery.

\section{External fixator}

This mode of treatment is not commonly used for treatment of these fractures, although there are some isolated reports in literature [42-44]. Biswas et al. reported treating periprosthetic fractures around the long-stem femoral component of Stanmore total knee replacement. In four of the five patients previous treatment had failed: skeletal traction in one and internal fixation in other four patients. They reported union in all five patients between 12 and 16 weeks in a good alignment without any major complications [42]. There are some case reports describing the use of Ilizarov external fixator in patients who were not deemed suitable for conventional treatment for supracondylar periprosthetic fractures. Both patients in these reports achieved solid union with good functional recovery [43, 44].

\section{Revision total knee arthroplasty}

This technique is used for an extremely distal and comminuted fracture where secure fixation cannot be achieved, or if the fracture is associated with a loose and unstable implant. The long-stemmed prosthesis provides stable fixation and allows patients to start early movements and weightbearing [22, 45, 46]. Cordeiro et al. reported their 
experience of treating periprosthetic fractures of the distal femur in ten patients. Two patients were treated nonoperatively, three were treated with internal fixation using plate and screws and five were treated by revision arthroplasty. Authors reported best results in revision group based on walking ability, range of motion and early rehabilitation [22]. Chen et al., in a review of 12 published reports including 195 patients, noted successful results in 10 out of 11 cases who were treated with revision arthroplasty as initial treatment method [45]. Srinivasan et al. reported results of using long-stem revision knee prosthesis in six periprosthetic and two complex distal femoral fractures. There were no intraoperative complications. All periprosthetic fractures healed at a mean time of 3.8 months. Postoperative complication included one case of posterior dislocation and one superficial infection. There was mean loss of extension of $7.7^{\circ}$, and the mean flexion achieved was $66^{\circ}\left(15-85^{\circ}\right)$. Authors emphasized the importance of achieving stability and early mobilisation in this difficult group of patients after revision arthroplasty [46].

Prosthetic replacement of the distal femur and structural allograft

The most difficult cases involve a loose prosthesis coupled with deficient metaphyseal bone stock rendering a basic revision procedure impossible. Such cases require excision of distal fracture fragment and replacement with either a distal femoral replacement prosthesis or a structural allograft. These treatment methods may also be required for nonunion following previously failed attempt at osteosynthesis. Distal femoral replacement implants should be considered as a limb-salvage option when other surgical options are not feasible. With modern hinged knee prosthesis there is increased freedom of rotation, which decreases prosthesis-bone stresses but still it does not match the function and longevity of the condylar components and therefore should be used only in low-demand patients [47]. Madsen et al. reported satisfactory results in four patients after revision total knee arthroplasty using a custom-made prosthesis at follow-up of 1-6 years with no major complications [48]. Springer et al. reported results of using modular rotating hinge knee prosthesis in 26 knees. This group included 11 cases of nonunion and 1 case of acute periprosthetic femur fractures. They reported an overall $31 \%$ incidence of different complications, including five cases of deep infection. However, there was significant improvement in overall range of motion, Knee Society scores and functional scores [49].

The use of a stemmed constrained revision component with structural distal femoral allograft composite has been described as an effective means of providing both implant and fracture stability [50-53]. This technique involves subperiosteal excision of involved distal femur with retention of soft tissue sleeve containing collateral ligaments and reconstruction with a structural allograft and a stemmed semiconstrained total knee prosthesis. Reconstruction of the distal femur with such a composite allows reattachment of host tissue, including the collateral ligaments, which provides additional stability to the knee postoperatively, thus circumventing the use of a hinged prosthesis. Kraay et al. published their results of using allograft-prosthesis composite in seven patients. They reported one case of dislocation and one popliteal artery injury, and two cases had persistent instability and required bracing. However, all components were well fixed at an average follow-up of 44 months [51]. Kassab et al. reported their experience of using distal allograft in periprosthetic fractures of the distal femur with poor bone stock in 12 patients. They achieved good interface union with no
Table 1 Summary of management of periprosthetic fracture of the femur

\begin{tabular}{lll}
\hline $\begin{array}{l}\text { Fracture } \\
\text { type }\end{array}$ & Description of fracture & Treatment recommendation \\
\hline I & $\begin{array}{c}\text { Undisplaced fracture and well-fixed } \\
\text { prostheses } \\
\text { Displaced fracture and well-fixed prostheses }\end{array}$ & Bracing, nonweightbearing \\
A. Good-quality bone & $\begin{array}{c}\text { Internal fixation using conventional plate, } \\
\text { intramedullary nail or locking plate }\end{array}$ \\
& $\begin{array}{l}\text { B. Poor-quality bone with osteopenia } \\
\text { and comminution }\end{array}$ & \\
1. Decent-size distal fragment & Intramedullary nail or locking plate \\
2. Extremely distal fracture & $\begin{array}{c}\text { Locking plate or buttress plate with strut } \\
\text { allograft }\end{array}$ \\
Displaced fracture, loose prostheses & Revision knee arthroplasty using a long- \\
A. No metaphyseal bone loss & stemmed femoral implant \\
& B. Metaphyseal bone loss or nonunion \\
following previous surgery & $\begin{array}{c}\text { Structural allograft-prostheses composite or } \\
\text { distal femoral replacement prosthesis }\end{array}$ \\
\hline
\end{tabular}


migration and loosening in nine out of ten patients available for review at a mean follow-up of 6 years [52]. More recently, Backstein et al. reported results of using 68 structural allograft around the knee for different indication including 17 periprosthetic femoral fractures. They did not separately report the results in periprosthetic fracture patient group, but overall they had only one nonunion, two cases of fractures through allograft and four cases of deep infection. Overall, $14.8 \%$ required revision at an average follow-up of 5.4 years [53].

In conclusion, management of periprosthetic fractures of the femur above total knee arthroplasty depends on displacement at the fracture site, bone quality, size of distal fragment and condition of implants. If the fracture is displaced and implants are well fixed, attempts are made to fix the fracture, whereas if implants are loose, consideration should be given to revision surgery. Management of periprosthetic fractures of the femur above total knee arthroplasties is summarized in Table 1.

\section{Conflict of interest None.}

Open Access This article is distributed under the terms of the Creative Commons Attribution Noncommercial License which permits any noncommercial use, distribution, and reproduction in any medium, provided the original author(s) and source are credited.

\section{References}

1. Herrera DA, Kregor PJ, Cole PA, Levy BA, Jonsson A, Zlowodzki M (2008) Treatment of acute distal femur fractures above a total knee arthroplasty: systematic review of 415 cases (1981-2006). Acta Orthop 79(1):22-27

2. Delport PH, Van Audekercke R, Martens M, Mulier JC (1984) Conservative treatment of ipsilateral supracondylar femoral fracture after total knee arthroplasty. J Trauma 24:846-849

3. Culp RW, Schmidt RG, Hanks G, Mak A, Esterhai JL, Heppenstall RB (1987) Supracondylar fracture of the femur following prosthetic knee arthroplasty. Clin Orthop 222:212-222

4. Figgie MP, Goldberg VM, Figgie HE, Sobel M (1990) The results of treatment of supracondylar fracture above total knee arthroplasty. J Arthroplasty 5:267-276

5. Rorabeck CH, Taylor JW (1999) Periprosthetic fractures of the femur complicating total knee arthroplasty. Orthop Clin North Am 30:265-277

6. Merkel KD, Johnson EW (1986) Supracondylar fracture of the femur after total knee arthroplasty. J Bone Joint Surg Am 68A:29-43

7. Cain PR, Rubash HE, Wissinger HA, McClain EJ (1986) Periprosthetic femoral fractures following total knee arthroplasty. Clin Orthop 208:205-214

8. Shawen SB, Belmont PJ Jr, Klemme WR, Topoleski LDT, Xenos JS, Orchowski JR (2003) Osteoporosis and anterior femoral notching in periprosthetic supracondylar fractures. A biomechanical study. J Bone Joint Surg Am 85-A:115-121

9. Lesh ML, Schneider DJ, Deol G, Davis B, Jacobs CR, Pellegrini VD Jr (2000) The consequences of anterior femoral notching in total knee arthroplasty: a biomechanical study. J Bone Joint Surg Am 82A:1096-1101
10. Sisto DJ, Lachiewicz PF, Insall JN (1985) Treatment of supracondylar fractures following prosthetic arthroplasty of the knee. Clin Orthop 196:265-272

11. McLaren AC, Dupont JA, Schroeber DC (1994) Open reduction internal fixation of supracondylar fractures above total knee arthroplasties using the intramedullary supracondylar rod. Clin Orthop 302:194-198

12. Hirsh DM, Bhalla S, Roffman M (1981) Supracondylar fracture of the femur following total knee replacement. Report of four cases. J Bone Joint Surg Am 63-A:162-163

13. Rand JA (1994) Supracondylar fracture of the femur associated with polyethylene wear after total knee arthroplasty. A case report. J Bone Joint Surg Am 76A:1389-1393

14. Ritter MA, Thong AE, Keating M, Faris PM, Meding JB, Berend ME et al (2005) The effect of femoral notching during total knee arthroplasty on the prevalence of postoperative femoral fractures and on clinical outcome. J Bone Joint Surg Am 87A:2411-2414

15. DiGioia AM, Rubash HE (1991) Periprosthetic fractures of the femur after total knee arthroplasty; a literature review and treatment algorithm. Clin Orthop 271:135-142

16. Rorabeck CH, Taylor JW (1999) Classification of periprosthetic fractures complicating total knee arthroplasty. Orthop Clin North Am 30:209-214

17. Kang-Il Kim, Egol KA, Hozack WJ, Parvizi J (2006) Periprosthetic fractures after total knee arthroplasties. Clin Orthop 446:167-175

18. Sochart DH, Hardinge K (1997) Nonsurgical management of supracondylar fracture above total knee arthroplasty. Still the nineties option. J Arthroplasty 12:830-834

19. Moran MC, Brick GW, Sledge CB, Dysart S, Chien E (1996) Supracondylar femoral fracture following total knee arthroplasty. Clin Orthop 324:196-209

20. Short WH, Hootnick DR, Murray DG (1981) Ipsilateral supracondylar femur fractures following knee arthroplasty. Clin Orthop 158:111-116

21. Healy WL, Siliski JM, Incavo SJ (1993) Operative treatment of distal femoral fractures proximal to total knee replacements. J Bone Joint Surg Am 75A:27-34

22. Cordeiro EN, Costa RC, Carazzato JG, Silva JDS (1990) Periprosthetic fractures in patients with total knee arthroplasties. Clin Orthop 252:182-189

23. Zehntner MK, Ganz R (1993) Internal fixation of supracondylar fractures after condylar knee arthroplasty. Clin Orthop 293:219-224

24. Tani Y, Inoue K, Kaneko H, Nishioka J, Hukuda S (1998) Intramedullary fibular graft for supracondylar fracture of the femur following total knee arthroplasty. Arch Orthop Trauma Surg 117:103-104

25. Wang JW, Wang CJ (2002) Supracondylar fractures of the femur above total knee arthroplasties with cortical allograft struts. J Arthroplasty 17:365-372

26. Kumar A, Chambers I, Maistrelli G, Wong P (2008) Management of periprosthethic fracture above total knee arthroplasty using intramedullary fibular allograft and plate fixation. J Arthroplasty 23(4):554-558

27. Koval KJ, Hoehl JJ, Kummer FJ, Simon JA (1997) Distal femoral fixation: a biomechanical comparison of the standard condylar buttress plate, a locked buttress plate and the 95 degree blade plate. J Orthop Trauma 11:521-524

28. Marti A, Fankhauser C, Frenk A, Cordey J, Gasser B (2001) Biomechanical evaluation of the less invasive stabilization system for the internal fixation of distal femur fractures. J Orthop Trauma 15:482-487

29. Kregor PJ, Hughes JL, Cole PA (2001) Fixation of distal femoral fractures above total knee arthroplasty utilizing the less invasive stabilization system (L.I.S.S.). Injury 32(Suppl 3):64-75 
30. Althausen PL, Lee MA, Finkemeier CG, Meehan JP, Rodrigo JJ (2003) Operative stabilization of supracondylar femur fractures above total knee arthroplasty: a comparison of four treatment methods. J Arthroplasty 18:834-839

31. Raab GE, Davis CM (2005) Early healing with locked condylar plating of periprosthetic fractures around the knee. J Arthroplasty 20:984-989

32. Ricci WM, Loftus T, Cox C, Borrelli J (2006) Locked plates combined with minimally invasive insertion technique for the treatment of periprosthetic supracondylar femur fractures above a total knee arthroplasty. J Orthop Trauma 20:190-196

33. Ritter MA, Keating EM, Faris PM, Medring JB (1995) Rush rod fixation of supracondylar fractures above total knee arthroplasties. J Arthroplasty 10:213-216

34. Jabczenski FF, Crawford M (1995) Retrograde intramedullary nailing of supracondylar femur fractures above total knee arthroplasty. A preliminary report of four cases. J Arthroplasty 10:95-101

35. Murrell GAC, Nunley JA (1995) Interlocked supracondylar intramedullary nails for supracondylar fractures after total knee arthroplasty. J Arthroplasty 10:37-42

36. Rolston LR, Christ DJ, Halpern A, O'Connor PL, Ryan TG, Uggen WM (1995) Treatment of supracondylar fractures of the femur proximal to a total knee arthroplasty. J Bone Joint Surg Am 77A:924-931

37. Smith WJ, Martin SL, Mabrey JD (1996) Use of a supracondylar nail for treatment of a supracondylar fracture of the femur following total knee arthroplasty. J Arthroplasty 11:210-213

38. Weber D, Pomeroy DL, Schaper LA, Badenhausen WE, Curry JI, Smith MW, Suthers KE (2000) Supracondylar nailing of distal periprosthetic femoral fractures. Int Orthop 24:33-35

39. Gliatis J, Megas P, Panagiotopoulos E, Lambiris E (2005) Midterm results of treatment with a retrograde nail for supracondylar periprosthetic fractures of the femur following total knee arthroplasty. J Orthop Trauma 19:164-170

40. Kumar A, Chambers I, Weiler P, Butt MS (2007) Supracondylar nailing of periprosthetic fractures above total knee arthroplasties. J Orthop Traumaol 8:177-181

41. Bong MR, Egol KA, Koval KJ, Kummer FJ, Su ET, Iesaka K, Bayer J, Di Cesare PE (2002) Comparison of the LISS and a retrograde-inserted supracondylar intramedullary nail for fixation of a periprosthetic distal femur fracture proximal to a total knee arthroplasty. J Arthroplasty 17:876-881
42. Biswas SP, Kurer MH, Mackenney RP (1992) External fixation for femoral shaft fracture after Stanmore total knee replacement. J Bone Joint Surg Br 74B:313-314

43. Simon RG, Brinker MR (1999) Use of Ilizarov external fixation for a periprosthetic supracondylar femur fracture. J Arthroplasty $14: 118-121$

44. Hurson C, Synnott K, McCormack D (2005) Above-knee Ilizarov external fixation for early periprosthetic supracondylar femoral fracture-a case report. Knee 12:145-147

45. Chen F, Mont MA, Bachner RS (1994) Management of ipsilateral supracondylar femur fractures following total knee arthroplasty. J Arthroplasty 9:521-526

46. Srinivasan K, Macdonald DA, Tzioupis CC, Giannoudis PV (2005) Role of long stem revision knee prosthesis in periprosthetic and complex distal femoral fractures: a review of eight patients. Injury 36:1094-1102

47. Harrison RJ Jr, Thacker MM, Pitcher JD, Temple HT, Scully SP (2006) Distal femur replacement is useful in complex total knee arthroplasty revisions. Clin Orthop 446:113-120

48. Madsen F, Kjaersgaard-Andersen P, Juhl M, Sneppen O (1989) A custom-made prosthesis for the treatment of supracondylar femoral fractures after total knee arthroplasty: report of four cases. J Orthop Trauma 3:332-337

49. Springer BD, Sim FH, Hanssen AD, Lewallen DG (2004) The modular segmental kinematic rotating hinge for nonneoplastic limb salvage. Clin Orthop 421:181-187

50. McAuley JP, Sanchez FL (1999) Periprosthetic fractures after major joint replacement. Knee-role and results of allografts. Orthop Clin North Am 30:293-303

51. Kraay MJ, Goldberg VM, Figgie MP, Figgie HE 3d (1992) Distal femoral replacement with allograft/prosthetic reconstruction for treatment of supracondylar fractures in patients with total knee arthroplasty. J Arthroplasty 7:7-16

52. Kassab M, Zalzal P, Azores GMS, Pressman A, Liberman B, Gross AE (2004) Management of periprosthetic femoral fractures after total knee arthroplasty using a distal femoral allograft. J Arthroplasty 19:361-368

53. Backstein D, Safir O, Gross A (2006) Management of bone loss: structural grafts in revision total knee arthroplasty. Clin Orthop 446:104-112 